ENTREVISTA 



\title{
Leonardo Padura: "El discurso de la nación no se puede hacer con una sola voz"
}

\author{
Por Karla Aguilar Velásquez ${ }^{1}$ \\ Universidad de Cartagena (Colombia)
}

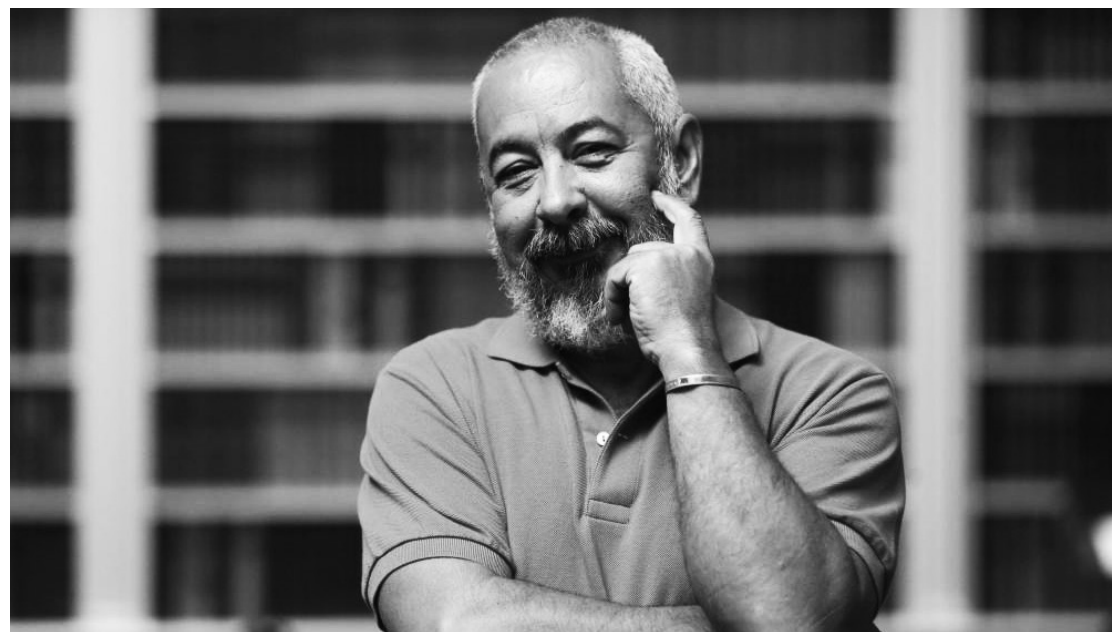

Leonardo Padura, narrador, guionista de cine, ensayista y periodista cubano es un referente indiscutible de la literatura cubana y latinoamericana contemporánea. A pesar de que se dio a conocer internacionalmente con la serie de novelas protagonizadas por el investigador Mario Conde, que conforman la tetralogía de Las Cuatro Estaciones, que ha sido llevada al cine y a la televisión, es autor de tres novelas más con el mismo personaje y de novelas de carácter histórico, como La novela de mi vida (2002) y El hombre que amaba a los perros (2009), su libro más difundido, premiado y comentado. Son sus inicios en la novela policial los que lo ubican en la novedad del continente, por las renovaciones estéticas y éticas que acercan sus novelas al fenómeno del neopolicial latinoamericano y terminan en Cuba con la tradición del policial comprometido, que había caracterizado las producciones del género desde la década de los 70 .

-Su obra tiene la particularidad de escribirse y popularizarse en el desarrollo mismo de la crisis económica, social e institucional

${ }^{1}$ Profesional en Lingüística y Literatura de la Universidad de Cartagena. e-mail: kaguilarv@unicartagena.edu.co 
del Periodo Espacial producto del fin del socialismo del Este y de la falta de planificación estatal ante las nuevas coordenadas mundiales. ¿Qué desafíos implicó escribir la saga de Mario Conde en un contexto de crítica y escepticismo imperante en las relaciones sociales y de convivencia en Cuba?

A la hora de escribir uno trata de encontrar una buena historia, de escribirla de la mejor manera posible y de expresar a través de ella determinadas preocupaciones, que a veces son pequeñas preocupaciones con posibilidades de una mayor proyección. He tratado de ser, sobre todo, un cronista de la vida cubana contemporánea. Como periodista. Como guionista de cine. Como novelista. A partir de este propósito entran otras posibilidades, otras necesidades y exigencias relacionadas con algunos de los elementos que mencionas. En una novela como El hombre que amaba los perros, el tema de la utopía y de la perversión de la utopía es central; como también ocurre en la serie de Mario Conde, que habla de un mundo donde la nostalgia hace ver más luminoso el pasado -no por gusto la primera novela de la saga, que fue escrita en 1991, se llama Pasado Perfecto-. Mario Conde puede mirarlo críticamente, pero, a la vez, por la presencia de la juventud, la esperanza y los sueños, lo ve con colores. Ante esto hay un presente que se va oscureciendo y que se oscurece a lo largo de los 90. A pesar de que las cuatro novelas -las primeras cuatro novelas: la saga de Las cuatro estaciones- ocurre en el año de 1989, yo estoy transitando los 90. La oscuridad de aquellos años se va transmitiendo a Mario Conde. Luego tenemos una novela como La neblina del ayer (2005), en la que ya se habla de la existencia de la crisis, de lo que significó la crisis y acerca de cómo se desmontó una estructura de homogeneidad que existía en el país. Comienza entonces una especie de implosión de la sociedad cubana.

-Si bien a niveles sociales, económicos y políticos el Período Especial representó el inicio de las relaciones constantes entre Cuba y el subdesarrollo, como si hubiera sido el fracaso rotundo del proyecto modernizador del país, a nivel artístico es también un momento que da paso a la novedad de las formas artísticas. Una explosión en el crear y en representación de nuevas voces más desligadas del aparato estatal. Hay más ironía y más experimentación. ¿Cómo vivió esta convivencia?

El tema del subdesarrollo fue central en la historia y en la sociedad cubanas durante cuarenta años. La película cubana más conocida de todos los tiempos se llama Memorias del subdesarrollo. Está basada en una novela de Edmundo Desnoes titulada igual. La reflexión sobre el subdesarrollo estuvo muy presente en Cuba. En los años 90 ya no 
se habló de subdesarrollo; se habló de crisis. No era posible hablar de si íbamos a intentar superar determinadas carencias. No. Había que luchar por la subsistencia y esto provocó que todo quedara en un plano más elemental. Pero a la vez se produce algo muy importante. Esa misma crisis creó una distancia entre las instituciones culturales y los creadores. ¿Por qué? Porque yo llegaba a una editorial cubana en los 90 con un libro y me decían: "Llévatelo para tu casa, porque no hay papel ni forma de publicarlo". Esto ocurrió con la plástica, el teatro y el cine. Ese espacio que se creó se llenó de libertad. Resultó paradójico que en un momento tan crítico de la vida económica y cotidiana cubana se creara un espacio creativo más propicio que aprovechamos todos. Mis novelas están en ese espíritu y las de muchos otros escritores también. Después aparecen Pedro Juan Gutiérrez, Wendy Guerra y Karla Suarez; se hace la película Fresa y chocolate (1993) -a partir de un relato de Senel Paz-; y las películas de Fernando Pérez. En el teatro y en la plástica existe todo un movimiento. Pienso que tiene que ver con eso, con una ganancia de espacios que los artistas consiguieron durante esos años y que, en definitiva, fue un espacio de libertad.

-Además de esta libertad, que tiene sus repercusiones en los formatos de novelas que reflexionan sobre este tiempo, es posible ver también en ellas una apertura a la diversidad de voces $e$ introducción de grupos marginados, que no encontraban lugar en la división revolucionario-contra-revolucionario. ¿El Período Especial posibilitó a la literatura explorar esos fantasmas identitarios que, en apariencia, la Revolución había ocultado?

Durante los años 60, 70 y 80 en Cuba hubo un ascenso social de muchos grupos marginados. También procesos lamentables. Porque mientras se daba un mayor espacio social, económico y familiar a la mujer, por ejemplo, mientras se eliminaba cualquier manifestación de discriminación racial, había, por otra parte, sectores que no tenían las mismas ganancias. Esto ocurría con personas que practicaban alguna religión o que tenían preferencias sexuales no consideradas "correctas". Hubo siempre esta tensión entre las cosas que avanzaban y las puertas que se cerraban. En los 90, con el quiebre económico producido en Cuba, nos quedamos prácticamente con un país paralizado. Afortunadamente, los espacios que se habían cerrado para estas personas que sufrían marginación, se abren definitivamente. Ya venía ocurriendo un proceso desde los años 80. Los 70 fueron terribles. Hubo una cierta progresión en ese aspecto respecto a los homosexuales y los religiosos. Y en los 90, bueno, todo explota, porque es una sociedad que se preocupa, fundamentalmente, por la supervivencia. Hay allí, por lo tanto, una serie de paradigmas que 
se van revisando. El arte se nutre de esa revisión. Mucha literatura escrita durante esos años en Cuba tiene que ver con el resurgimiento de la prostitución, con la emigración y los balseros, con la gente que escapa, con las dificultades económicas... Tanto la literatura como el cine se acercan más a la realidad. Hubo un espacio anterior que no permitía este acercamiento.

- ¿Acercamiento que, quizá, resulta de la separación entre "nación" y "gobierno"? Es decir, que se crean nuevos parámetros de pertenencia a un país, sin que eso signifique estar de acuerdo con las políticas estatales.

En el caso cubano eso no ocurre. En el caso cubano el gobierno representa la nación y lo complicado es cómo una persona individual puede ser representativa de la nación sin tener un pensamiento ortodoxo con respecto a la política. Hay muchos discursos diferentes: está el discurso político de personas, de artistas que salieron de Cuba, un discurso que es abiertamente contrario al gobierno, pero que no por ello estas personas dejan de ser cubanas. Hay personas que viven fuera de Cuba y no tienen tal discurso en su literatura o en su arte, pero sí en determinadas manifestaciones públicas. Dentro de Cuba ocurre lo mismo. Así que que hay una enorme cantidad de posibilidades y el carácter heterogéneo de esas posibilidades creativas o discursivas son importantes para terminar de construir la nación. El discurso de la nación no se puede hacer con una sola voz. Tiene que ser con muchas voces.

-En esta conversación han sido inevitables las continuas relaciones entre literatura y política. De hecho, es muy común que a los escritores, artistas y cineastas cubanos se les pregunte por la realidad de su país. Se llega incluso a pensar que sus producciones pueden considerarse como el retrato auténtico de momentos históricos, casi como documentos. Usted, que ha trabajado la historia desde todos sus espectros -lo hizo en la saga del teniente Mario Conde; lo hace ahora en la reconversión definitiva a la novela histórica-, ¿cree que la literatura puede producir verdades históricas?

La literatura tiene que primero ser literatura y después tener las otras pretensiones. Si una de esas posibilidades es convertirse en un documento que clarifica la realidad o que define la realidad, o que es capaz de expresarla y explicársela a otros, bienvenido. Pero el compromiso estético consigo misma es el primero que debe cumplir para que pueda cumplir los otros. Si una obra es fallida estéticamente, difícilmente podrá cumplir los otros propósitos. Hay casos, sabemos, 
de películas muy mal hechas, o de novelas muy mal escritas, que ofrecen una cantidad de información y se convierten precisamente en un documento, pero valen como documento, no como obra de arte. Es preferible que una obra de arte valga como obra de arte y luego como documento.

-Usted afirmaba, en el discurso de recibimiento del Premio Princesa de Asturias, que ser escritor es un compromiso artístico y civil. ¿Cuál sería el límite que distingue a un escritor consciente de sus ideologías a la hora de escribir y a un escritor que convierte su obra en manifiesto o panfleto?

Escribir una obra únicamente para cumplir con una exigencia o necesidad política no resulta lo más conveniente. Cada cual puede tener el derecho a tomar la opción que desee y hay que respetarlo. En mi caso específico, trato de cumplir una propuesta estética, trato de que mi obra tenga una proyección social, y en última instancia, una lectura política. La lectura política no la pongo nunca, ni la pondré nunca en primer término. No quiero hacer un documento. Quiero hacer una novela. Quiero hacer una obra de arte. Convertir el arte en una forma expresa de denuncia puede disminuir esa capacidad de generar belleza que debe tener la literatura y el arte en general. Hay que afectar primero los sentimientos de quien recibe la obra. Hay que comunicarse con su parte inconsciente y llegar a la parte consciente de ese consumidor de arte. Esto se logra a través del ejercicio estético. El mensaje político o la visión social tienen que estar incluidos dentro de ese mensaje. 
